\title{
HUBUNGAN PENGETAHUAN IBU TENTANG EFEK SAMPING DENGAN MOTIVASI PENGGUNAAN IUD PADA PUS (PASANGAN USIA SUBUR) DI DESA BENDASARI KECAMATAN SADANANYA TAHUN 2017
}

\author{
Nova Winda Setiati ${ }^{1}$ \\ ${ }^{1}$ Program Studi Kebidanan Fakultas Ilmu Kesehatan Universitas Galuh Ciamis \\ novawindasetiati@gmail.com \\ (Diterima 9-12- 2018; disetujui 15-12-2018; dipublish 31-1-2019)
}

\begin{abstract}
ABSTRAK
Indonesia merupakan negara berkembang dengan jumlah penduduk sebanyak 252.124.458 jiwa dengan luas wilayah 1.913.378,68 km2 dan kepadatan penduduk sebesar 131,76 jiwa/km2 (Depkes RI, 2014).Provinsi Jawa Barat masih menjadi salah satu provinsi teratas sebagai penyumbang angka kematian ibu dan bayi di Indonesia. Menurut laporan Dinas Kesehatan Provinsi Jawa Barat di tahun 2015 jumlah kasus kematian ibu melahirkan karena hamil, persalinan, dan nifas meningkat cukup tajam dari 748 kasus di tahun 2014 menjadi 823 kasus di 2015. Kondisi serupa juga terjadi pada bayi baru lahir, yakni meningkat dari 3098 kasus di tahun 2014 menjadi 3369 kasus di tahun 2015. Rata-rata setiap hari provinsi Jawa Barat pada tahun 2015 kehilangan 2 ibu dan 9 bayi akibat kematian tersebut. (KemenKes Jabar, 2016) Kontrasepsi IUD merupakan salah satu jenis kontrasepsi efektif, yaitu pemakaian IUD dengan satu kali penggunaan untuk jangka yang lama. Perkembangan bentuk IUD serta kesadaran yang meningkat akan perlunya pengendalian kesuburan dengan teknik penggunaan yang benar, maka kini IUD telah dapat di terima secara luas di kalangan masyarakat (wiknjosastro. 2007). Untuk mengetahui tentang hubungan pengetahuan ibu tentang efeksamping dengan motivasi penggunaan IUD pada PUS (Pasangan Usia Subur) di Desa Bendasari Kecamatan Sadananya Tahun 2017. Populasi dalam penelitian ini adalah adalah PUS (Pasangan Usia Subur) yang ada di Desa Bendasari Kecamatan Sadananya sebanyak 787 orang. dan kemudian ditarik sampel menggunakan simple random sampling menjadi 98 orang. Hasil penelitian didapatkan hasil bahwa terdapat hubungan pengetahuan Ibu tentang efek samping penggunaan IUD dengan Motivasi Ibu terhadap penggunaan alat kontrasepsi IUD dengan nilai $\rho$ value 0.00 . Disarankan bagi responden yang masih memiliki tingkat pengetahuan yang kurang supaya menambah pengetahuanya dengan cara lebih banyak membaca ataupun mencari tahu lewat media informasi yang ada.
\end{abstract}

Kata kunci : PUS, Pengetahuan, Alat Kontrasepsi, IUD

\begin{abstract}
Indonesia is a developing country with a population of 252,124,458 people with an area of $1,913,378.68 \mathrm{~km} 2$ and a population density of 131.76 inhabitants / $\mathrm{km} 2$ (MOH, 2014). The province of West Java is still one of the top provinces as a contributor Maternal and infant mortality rate in Indonesia. According to the West Java Health Service report in 2015, the number of maternal mortality cases due to pregnancy, childbirth and childbirth has increased significantly from 748 cases in 2014 to 823 cases in 2015. Similar conditions also occur in newborns, 3098 cases in 2014 to 3369 cases in 2015. On average every day the province of West Java in 2015 lost 2 mothers and 9 babies due to the death. (KemenKes Jabar, 2016) IUD contraception is one type of effective contraception, namely the use of IUD with one-time use for long periods. The development of IUD shape and increased awareness of the need for fertility control with proper usage techniques, so now IUD has been widely accepted among the people (wiknjosastro 2007). Based on the results of interviews with family planning office officer Sadananya Puskesmas in get results that Bendasari Village is the village with the least contraceptive apparatus in comparison with other villages in the
\end{abstract}


District Sadananya on the grounds people there less trust in KB. So that this year is being pioneered Village $K B$ in Bendasari Village. To know about the relationship of mother knowledge about efeksamping with motivation of IUD use at PUS (Couple Age) in Countryside of Bendasari District of Sadananya Year 2017. Population in this research is EFA (Eligible for Age) In Bendasari village, Sadananya sub-district as many as 787 people. And then drawn the sample using simple random sampling to 98 people. The result showed that there was a correlation between Mother's knowledge about side effect of IUD use with Mother Motivation on IUD contraceptive use with value $\rho$ value 0.00. It is recommended for the respondents who still have the level of knowledge that is less in order to increase pengetahuanya by way of more reading or finding out through the existing information media

Keywords $\quad$ :EFA, Knowledge, Contraception, IUD

\section{PENDAHULUAN}

Indonesia merupakan sebuah negara berkembang dengan jumlah penduduk sebanyak 252.124.458 jiwa dengan luas wilayah $1.913 .378,68 \quad \mathrm{~km}^{2}$ dan kepadatan penduduk sebesar 131,76 jiwa/km² (Depkes RI, 2014).

Provinsi Jawa Barat masih menjadi salah satu provinsi teratas sebagai penyumbang angka kematian ibu dan bayi di Indonesia. Menurut laporan Dinas Kesehatan Jawa Barat di tahun 2015 disampaikan bahwa jumlah kasus kematian ibu melahirkan karena hamil, persalinan, dan nifas meningkat cukup tajam dari 748 kasus di tahun 2014 menjadi 823 kasus di 2015. Kondisi serupa juga terjadi pada bayi baru lahir, yakni meningkat dari 3098 kasus di tahun 2014 menjadi 3369 kasus di tahun 2015. Rata-rata setiap hari provinsi Jawa Barat pada tahun 2015 kehilangan 2 ibu dan 9 bayi akibat kematian tersebut. (KemenKes Jabar , 2016)

Masalah yang terdapat di Indonesia adalah laju pertumbuhan penduduk yang relatif masih tinggi. Perkiraan penduduk pertengahan 2013 sebesar 248,8 juta jiwa dengan laju pertumbuhan penduduk sebesar 1,48\%. Laju pertumbuhan ditentukan oleh kelahiran dan kematian ibu dengan adanya perbaikan pelayanan kesehatan menyebabkan tingkat kematian ibu dan bayi rendah, sedangkan tingkat kelahiran tetap tinggi hal ini penyebab utama ledakan penduduk. Cara menekan jumlah penduduk dengan menggalakan program Keluarga Berencana (KB) (BPS, 2013).

Program KB Nasional mempunyai kontribusi penting dalam upaya meningkatkan kualitas penduduk. Kontribusi program KB Nasional tersebut dapat di lihat pada pelaksanaan program making pregnancy safer (MPS) di Indonesia adalah bahwa setiap kehamilan harus merupakan kehamilan yang diinginkan. Untuk mewujudkan pesan kunci tersebut $\mathrm{KB}$ merupakan upaya pelayanan kesehatan preventif yang paling dasar dan utama. Untuk mengoptimalkan manfaat keluarga berencana bagi kesehatan, pelayanannya harus digabungkan dengan pelayanan kesehatan reproduksi yang telah tersedia (Depkes RI, 2012). 
Pelayanan Keluarga Berencana yang merupakan salah satu di dalam paket Pelayanan Kesehatan Reproduksi Esensial perlu mendapat perhatian yang serius, karena dengan mutu pelayanan Keluarga Berencana berkualitas diharapkan akan dapat meningkatkan tingkat kesehatan dan kesejahteraan. Dengan telah berubahnya paradigma dalam pengolahan masalah kependudukan dan pembangunan dari pendekatan pengendalian populasi dan penurunan fertilitas menjadi pendekatan yang berfokus pada kesehatan reproduksi serta har reproduksi. Maka pelayanan Keluarga Berencana harus menjadi lebih berkualitas serta memperhatikan hak-hak dari klien/ masyarakat dalam memilih metode kontrasepsi yang diinginkan. (Saifuddin, 2012).

Pada saat sekarang ini telah banyak beredar berbagai macam alat kontrasepsi. Macam-macam metode kontrasepsi tersebut adalahintra uterine devices (IUD), impalnt, suntik, kondom, metode operatif untuk wanita (MOW), metode operatif untuk pria (MOP), dan kontrasepsi pil. Alat kontrasepsi hendaknya memenuhi syarat yaitu aman pemakaiannya dan dapat dipercaya, efek samping yang merugikan tidak ada, lama kerjanya dapat di atur menurut keinginan, tidak mengganggu hubungan seksual, harganya murah dan dapat diterima oleh pasangan suami istri (Saifuddin, 2012).

Kontrasepsi IUD merupakan salah satu jenis kontrasepsi efektif, yaitu pemakaian IUD dengan satu kali penggunaan untuk jangka yang lama.

Perkembangan bentuk IUD serta kesadaran yang meningkat akan perlunya pengendalian kesuburan dengan teknik penggunaan yang benar, maka kini IUD telah dapat di terima secara luas di kalangan masyarakat (wiknjosastro. 2007)

Berdasarkan pra survey yang di lakukan di Puskesmas Sadananya diketahui bahwa jumlah PUS (Pasangan Usia Subur) di Wilayah Kerja Puskesmas Sadananya Tahun 2016 sebanyak sebanyak 8150, dengan jumlah Akseptor KB IUD sebanyak 931 orang $11,42 \%$. Desa Bendasari mempunyai jumlah Akseptor KB IUD sebanyak 69 orang $8,84 \%$ yang menggunakan KB IUD. Berdasarkan data tersebut diketahui bahwa jumlah presentase Akseptor KB IUD di Desa Bendasari cukup rendah di bandingkan dengan desa lain di Wilayah Kerja Puskesmas Sadananya.

Berdasarkan uraian dari latar belakang di atas, maka permasalahan yang diungkap dalam penelitian ini adalah "Adakah hubungan pengetahuan ibu tentang efeksamping dengan motivasi penggunaan IUD pada PUS (Pasangan Usia Subur) di Desa Bendasari Kecamatan Sadananya Tahun 2017?”

\section{METODE PENELITIAN}

Penelitian ini termasuk jenis penelitian yang bersifat Deskriptif Korelasional. Data akan disajikan dalam bentuk deskripsi tentang hubungan pengetahuan ibu tentang efeksamping 
dengan motivasi penggunaan IUD pada PUS (Pasangan Usia Subur) di Desa Bendasari Kecamatan Sadananya Tahun 2017.

Populasi dalam penelitian ini adalah PUS (Pasangan Usia Subur) yang ada di Desa Bendasari Kecamatan Sadananya sebanyak 787 orang. Teknik pengambilan sampel dalam penelitian ini adalah simple random sampling maka yang menjadi sampel penelitian 98 responden.

Analisis data dilakukan melalui dua tahapan yaitu analisis univariat dan analisis bivariat. Analisis data yang digunakan dengan bivariat yang dilakukan terhadap 2 variabel yang diduga berhubungan atau bertoleransi (Notoatmodjo, 2002), sehingga untuk mencari hubungan antara variabel pengetahuan efeksamping dengan motivasi pengguna IUD digunakan uji statistik Chi-Square.

\section{HASIL DAN DISKUSI}

Penelitian dilaksanakan di Desa Bendasari Kecamatan Sadananya selama 30 hari setelah mendapat izin penelitian. Gambaran pengetahuan ibu tentang efek samping penggunaan IUD di Desa Bandasari Kecamatan Sadananya ditunjukkan pada tabel 1:

\begin{tabular}{clcc}
\hline No & \multicolumn{1}{c}{ Tingkat Pengetahuan } & Frekuensi & Persentase \\
\hline $\mathbf{1}$ & Baik & 19 & 19.4 \\
\hline $\mathbf{2}$ & Cukup & 29 & 29.6 \\
\hline $\mathbf{3}$ & Kurang & 50 & 51.0 \\
\hline Jumlah & $\mathbf{9 8}$ & $\mathbf{1 0 0 \%}$ \\
\hline
\end{tabular}

Sumber : Data Primer (diolah Juni 2017)

Motivasi Ibu terhadap penggunaan alat kontrasepsi IUD dapat digambarkan pada tabel 2 berikut :

\begin{tabular}{clccc}
\hline No & & Motivasi & Frekuensi & Persentase \\
\hline $\mathbf{1}$ & Kuat & 23 & 23.5 \\
\hline $\mathbf{2}$ & Sedang & 25 & 25.5 \\
\hline $\mathbf{3}$ & Lemah & 50 & 51.0 \\
\hline Jumlah & $\mathbf{9 8}$ & $\mathbf{1 0 0 \%}$ \\
\hline
\end{tabular}

Sumber : Data Primer (diolah Juni 2017)

Analisis bivariat yaitu pengetahuan ibu tentang efek samping penggunaan IUD dan motivasi ibu dalam penggunaan alat kontrasepsi IUD, analisis bivariat ini dapat digambarkan dalam tabel 3 berikut;

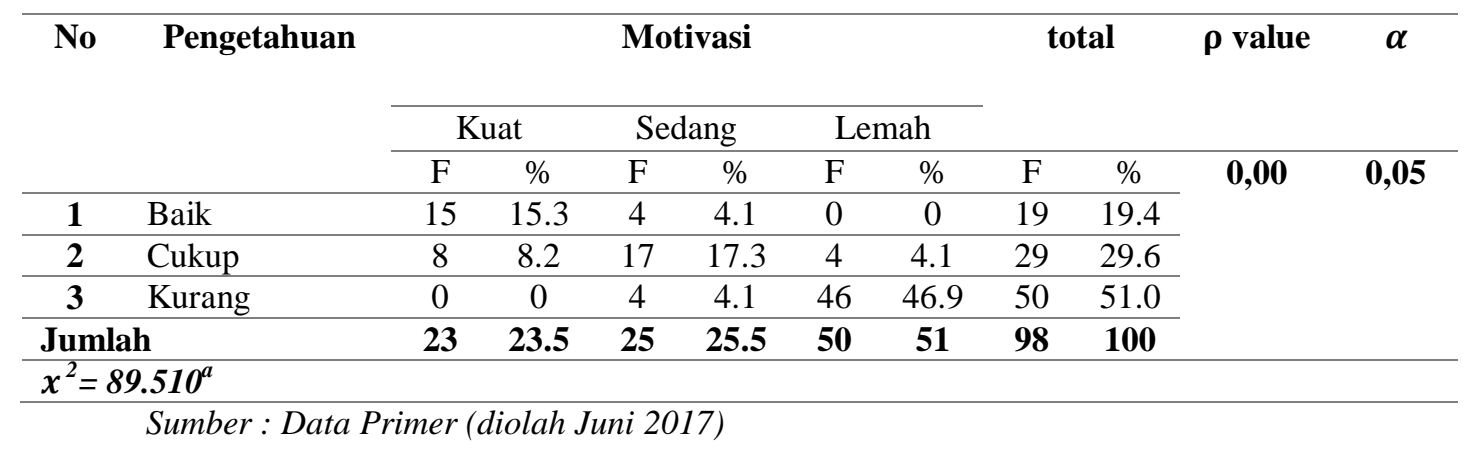


Dari hasil penelitian didapatkan data bahwa terdapat hubungan yang bermakna antara pengetahuan Ibu tentang efek samping penggunaan IUD dengan motivasi penggunaan alat kontrasepsi IUD di Desa Bendasari Kecamatan Sadananya Kabupaten Ciamis tahun 2017, hal ini bisa dilihat dari besarnya motivasi yang lemah pada responden bersandingan pengetahuan respoden yang kurang. Hal ini menurut Sunoto (2009) dikarenakan bahwa seseorang yang memiliki pengetahuan yang kurang tentang tindakan kesehatan cenderung akan melakukan pilihan yang tepat untuk kesehatannya, begitupun sebaliknya, seseorang yang memiliki pengetahuan yang baik akan cenderung memilih tindakan kesehatan yang baik pula.

Hasil penelitian ini juga sejalan dengan teori Notoatmodjo (2010) pengetahuan kognitif merupakan domain yang sangat penting untuk terbentuknya tindakan atau motivasi seseorang, dengan pengetahuan yang diperoleh, seseorang akan mengetahui manfaat dari saran atau nasihat sehingga akan termotivasi dalam usaha meningkatkan status kesehatan.

Hasil penelitian ini didukung juga oleh hasil penelitian Nurwahyuningsih (2011) yang mendapatkan kesimpulan bahwa terdapat hubungan antara pengetahuan dengan penggunaan $\mathrm{KB}$ IUD. Penggunaan KB IUD ini mencerminkan bahwa seseorang memiliki dorongan yang baik dari dalam dirinya melalui hasil pengetahuan yang dimiliki. Hasil penelitian Ely (2013) menunjukkan bahwa terdapat hubungan yang bermakna antara pengetahuan terhadap rendahnya penggunaan IUD dan pengetahuan merupakan faktor yang paling dominan terhadap rendahnya penggunaan IUD. Pada penelitian yang bersangkutan, tidak tertuliskan bahwa terdapat hubungan pengetahuan dengan motivasi dalam menggunakan IUD, namun perilaku manusia merupakan refleksi dari berbagai gejala kejiwaan seperti pengetahuan, keinginan, kehendak, minat, motivasi, persepsi, sikap dan sebagainya.

Dalam penelitian ini terdapat perbedaan tingkat pengetahuan responden hal ini bisa disebakan oleh beberapa faktor anatara lain: menurut Notoatmodjo (2010) pengetahuan adalah merupakan hasil tahu, hal ini setelah orang melakukan penginderaan terhadap suatu obyek tertentu. Pengetahuan ibu dapat diperoleh dari beberapa faktor baik formal seperti pendidikan yang didapat disekolah maupun non formal.Tingkat pendidikan seseorang akan mempengaruhi pengetahuan yang didapat karena pendidikan mempengaruhi proses belajar, makin tinggi tingkat pendidikan seseorang, makin mudah orang tersebut menerima informasi.

Faktor selanjutnya yang mempengaruhi perbedaan pengetahuan 
ibu tentang kontrasepsi IUD adalah paparan informasi, menurut Fathiyani (2013) Informasi yang diperoleh baik dari pendidikan formal maupun nonformal dapat memberikan pengaruh jangka pendek (immediate impact) sehingga menghasilkan perubahan atau peningkatan pengetahuan yang dapat diperoleh dari berbagai bentuk media massa.

Faktor yang lainya adalah pengalaman, menurut Fathiyani (2013) bahwa pengalaman ibu dalam menggunakan alat kontrasepsi dapat memberikan penegtahuan yang baik sehingga dapat menentukan pemilihan alat kontrasepsi yang cocok untuk dirinya, hal ini seseuai juga dengan teori yang dikemukakan Notoatmodjo (2010) bahwa salah satu cara untuk mendapatkan pengetahuan dengan cara metode non ilmiah adalah berdasarkan pengalaman pribadi.

Dari semua pembahasan ini, peneliti mengambil kesimpulan bahwa dari hasil pengetahuan akan memberikan dorongan dalam diri seseorang (motivasi) untuk, mengambil suatu tindakan. Dengan demikian, dapat diketahui bahwa pengetahuan yang baik dan benar mengenai IUD akan memberikan dorongan atau motivasi dalam menggunakan IUD.

Hal tersebut berdasar kepada hasil penelitian yang menunjukan bahwa responden yang mempunyai pengetahuan yang baik yaitu sebanyak 15 orang (15.3\%) memiliki motivasi yang kuat, responden yang memiliki tingkat pengetahuan yang cukup sebanyak 8 orang $(8.2 \%)$ memiliki motivasi yang kuat dan tidak seorang pun responden yang memiliki tingkat pengetahuan yang kurang memiliki motivasi yang kuat, hal ini menurut (Notoatmodjo, 2010) bahwa motivasi adalah suatu usaha yang disadari pengetahuan yang mempengaruhi tingkah laku seseorang agar ia bergerak hatinya untuk bertindak melakukan sesuatu sehingga mencapai hasil dan tujuan tertentu.

\section{KESIMPULAN}

Uraian pembahasan penelitian ini dapat disimpulkan bahwa terdapat ada hubungan antara pengetahuan Ibu tentang efek samping penggunaan IUD dengan Motivasi Ibu terhadap penggunaan alat kontrasepsi IUD denga nilai $\rho$ value adalah 0,00 .

\section{SARAN}

Hasil penelitian ini dapat dijadikan sebagai mampu memberikan informasi dan masukan kepada masyarakat tentang efeksamping dan motivasi penggunaan alat kontrasepsi IUD sehingga dapat meningkatkan kesadaran PUS (Pasangan Usia Subur) untuk menggunakan alat kontrasepsi IUD.

\section{REFERENSI}

Arikunto, Suharsimi. 2010. Prosedur Penelitian Suatu Pendekatan Praktek. Bandung: Rineka Cipta.

Azwar, Saifudin, 2013. Sikap Manusia: Teori dan Pengukurannya. Yogyakarta: Liberty. 
Depkes, 2011. Data Penduduk Sasaran Program Pembangunan Kesehatan Tahun 2007-2011. Jakarta: Depkes RI.

Digital, 2016. Penilaian pengetahuan. Tersedia dalam http://www.kampus-digital.com. Diakses pada tanggal 22 Februari 2017

Ely R,2013. Perbedaan Pengetahuan

Sebelum Dan Sesudah Penyuluhan

Tentang Kontrasepsi Implan (Studi

Pada Wus Di Rw Iv Desa Wonolopo

Kecamatan Mijen Kota Semarang).

2013 [Diakses tanggal 20 Juni

2017]. Didapat dari:

http://www.jurnal.unimus.ac.id

Fathiyani 2013 Hubungan Pengetahuan

Dengan Motivasi Ibu Nifas Dalam Menggunakan Kb IUD Di Wilayah Kerja Puskesmas Kayen Kabupaten Pati. Ungaran: Akademi Kebidanan Ngudi Waluyo

Hanafiah. 2005. Alat Kontrasepsi Dalam Rahim (AKDR)/IUD. Jurnal Handayani. 2012. Asuhan Keluarga Berencana. Jakarta: Rineka Cipta. Keperawatan Sumatera Utara.

Imbarwati. 2010. Gambaran persepsi ibu tentang rasa aman terhadap pemakaian IUD di Desa Tegalrejo Kecamatan Purwerejo [Tesis]. Semarang : UNDIP.

Kusumaningrum, R. 2009. Faktor-Faktor yang Mempengaruhi Pemilihan Jenis Kontrasepsi yang Digunakan Pasangan Usia Subur [Skripsi]. Semarang: UNDIP.
Notoatmodjo,S. 2012. Metode Penelitian

Kesehatan. Jakarta: Rineka Cipta.

Notoadmojo, S. (2011). Pengantar Pendidikan Kesehatan dan Ilmu Perilaku. Jakarta: Rineka Cipta.

Nurwahyuningsih 2011 Hubungan Tingkat Pengetahuan Pasangan

Usia Subur Tentang Alat Kontrasepsi IUD dengan Pemilihan Kontrasepsi IUD di Desa Tajuk Kecamatan Getasan Kabupaten Semarang [KTI]. Ungaran: Akademi Kebidanan Ngudi Waluyo;

Prawirohardjo. (2011). Ilmu Kebidanan. Jakarta: Salemba Mardika

Purwanto, 2013. Model-Model Pembelajaran. Jakarta: PT Raja Grafindo Persada.

Saifudin. (2011). Buku Panduan Praktis Pelayanan Kontrasepsi. Jakarta: Bina Pustaka Sarwono Prawirohardjo;

Sunoto. (2005). Di Balik Kontrovensi ASISusu Formula. Jakarta: Yayasan Obor.

Sugiyono, 2010.Statistik Untuk Penelitian, Alfabeta, Bandung.

Suparyanto, 2014. Pengertian Pengetahuan. Tersedia dalam http://dr-suparyanto.blogspot.co.id.

Diakses pada tanggal 14 februari 2017

Suparyanto, 2012. Pengertian Motivasi. Tersedia dalam http://dr-suparyanto.blogspot.co.id. Diakses pada tanggal 23 februari 2017 
Jurnal Keperawatan Galuh

Volume : 1-Nomor : 1 Tahun : 2019

Suparyanto, 2012. Pengukuran Motivasi.

Trandil, 2015. Pengertian dan tingkat

Tersedia dalam pengetahuan. Tersedia dalam http://dr-suparyanto.blogspot.co.id. http://www.trendilmu.com. Diakses

Diakses pada tanggal 17 februari pada tanggal 18 februari 2017 2017 